\title{
Correction to: The New-Found WAE Petroglyphs at Aznā, Lorestan Province, Western Iran
}

Behzad Hoseyni Sarbisheh (D), Faculty of Humanities, Tarbiat Modares University, Tehran, Iran

E-mail: behzadsarbisheh@gmail.com

Samer Nazari, University of Tehran, Tehran, Iran

E-mail: nazarisamer@yahoo.com

Marzieh Sha'rbaf, University of Tehran, Tehran, Iran

E-mail: marzieh.sharbaf@yahoo.com

Published online: 7 October 2020

Correction to: Archaeologies: Journal of the World Archaeological Congress (ㄷ 2020) https://doi.org/10.1007/s11759-019-09387-2

Unfortunately, in the original version of this published article were wrongly displayed one of the co-author's name. Instead of Dr. Marzieh Sha'rbaf it has been wrongly displayed as Marziyeh Shaerbaf. This has been corrected by publishing this correction article.

Publisher's Note Springer Nature remains neutral with regard to jurisdictional claims in published maps and institutional affiliations. 